\title{
Heterozygous defects in PAX6 gene and congenital hypopituitarism
}

\author{
Masaki Takagi ${ }^{1,2}$, Keisuke Nagasaki ${ }^{3}$, Ikuma Fujiwara ${ }^{4}$, Tomohiro Ishii' ${ }^{2}$, \\ Naoko Amano' ${ }^{2}$, Yumi Asakura ${ }^{5}$, Koji Muroya ${ }^{5}$, Yukihiro Hasegawa', \\ Masanori Adachi ${ }^{5}$ and Tomonobu Hasegawa ${ }^{2}$
}

${ }^{1}$ Department of Endocrinology and Metabolism, Tokyo Metropolitan Children's Medical Center, Tokyo, Japan, ${ }^{2}$ Department of Pediatrics, School of Medicine, Keio University, 35 Shinanomachi, Shinjuku-ku, Tokyo 160-8582, Japan, ${ }^{3}$ Division of Pediatrics, Department of Homeostatic Regulation and Development, Graduate School of Medicine and Dental Sciences, Niigata University, Niigata, Japan, ${ }^{4}$ Department of Pediatrics, School of Medicine, Tohoku University, Miyagi, Japan and ${ }^{5}$ Department of Endocrinology and Metabolism, Kanagawa Children's Medical Center, Yokohama, Japan
Correspondence should be addressed to T Hasegawa Email thaseg@a6.keio.jp

\begin{abstract}
Background: The prevalence of congenital hypopituitarism $(\mathrm{CH})$ attributable to known transcription factor mutations appears to be rare and other causative genes for $\mathrm{CH}$ remain to be identified. Due to the sporadic occurrence of $\mathrm{CH}$, de novo chromosomal rearrangements could be one of the molecular mechanisms participating in its etiology, especially in syndromic cases.

Objective: To identify the role of copy number variations (CNVs) in the etiology of $\mathrm{CH}$ and to identify novel genes implicated in $\mathrm{CH}$.

Subjects and methods: We enrolled 88 (syndromic: 30; non-syndromic: 58) Japanese $\mathrm{CH}$ patients. We performed an array comparative genomic hybridization screening in the 30 syndromic $\mathrm{CH}$ patients. For all the 88 patients, we analyzed PAX6 by PCR-based sequencing.

Results: We identified one heterozygous 310-kb deletion of the PAX6 enhancer region in one patient showing isolated GH deficiency (IGHD), cleft palate, and optic disc cupping. We also identified one heterozygous 6.5-Mb deletion encompassing OTX2 in a patient with bilateral anophthalmia and multiple pituitary hormone deficiency. We identified a novel PAX6 mutation, namely p.N116S in one non-syndromic $\mathrm{CH}$ patient showing IGHD. The p.N116S PAX6 was associated with an impairment of the transactivation capacities of the PAX6-binding elements.

Conclusions: This study showed that heterozygous PAX6 mutations are associated with $\mathrm{CH}$ patients. PAX6 mutations may be associated with diverse clinical features ranging from severely impaired ocular and pituitary development to apparently normal phenotype. Overall, this study identified causative CNVs with a possible role in the etiology of $\mathrm{CH}$ in $<10 \%$ of syndromic $\mathrm{CH}$ patients.
\end{abstract}

\section{Introduction}

The proliferation and terminal differentiation of the anterior pituitary gland are strongly influenced by the precise spatial and temporal expression of transcription factors $(1,2,3)$. Mutations in these transcription factors result in various types of congenital hypopituitarism $(\mathrm{CH})$, ranging from isolated growth hormone deficiency (IGHD) to multiple pituitary hormone deficiency (MPHD) $(1,2,3)$.
European Journal of Endocrinology

(2015) 172, 37-45
(C) 2015 European Society of Endocrinology Printed in Great Britain
Previous studies have shown that these transcriptional factor mutations are rare among $\mathrm{CH}$ patients. In Japan, Takagi et al. (4) identified three mutation carriers (two LHX4 mutations and one POU1F1 mutation) in a total of $91 \mathrm{CH}$ (14 patients had IGHD, whereas 77 patients had MPHD) patients (3.3\%). Reynaud et al. (5) reported a mutation prevalence of $13.3 \%$ in a study population of 
165 MPHD patients from the international GENHYPOPIT network. These results imply the rarity of pathological abnormalities in the previously known genes in $\mathrm{CH}$ patients and strongly suggest that other causative genes for $\mathrm{CH}$ remain to be identified in most patients.

Several cases of $\mathrm{CH}$ with submicroscopic chromosomal rearrangements, such as $20 \mathrm{p} 11$ deletions and 22q12.3q13.3 duplication, whose definitive causative genes responsible for $\mathrm{CH}$ are not fully captured, have been reported $(6,7,8)$. These patients were syndromic and showed extra pituitary clinical spectra, including dysmorphic faces, midline defects, and intellectual disability. Because most cases of $\mathrm{CH}$ are sporadic, we hypothesized that de novo chromosomal rearrangements could be a certain fraction of the molecular mechanisms participating in the etiology, especially in syndromic cases. Therefore, we decided to perform a genome-wide screening for submicroscopic anomalies in our syndromic $\mathrm{CH}$ cohort to determine the role of copy number variations (CNVs) in the etiology of $\mathrm{CH}$, and to identify new candidate loci and thus novel candidate genes for $\mathrm{CH}$.

\section{Subjects and methods}

\section{Subjects}

This study population consisted of 88 patients with $\mathrm{GH}$-treated $\mathrm{CH}$. The inclusion criteria were as follows: i) severe $\mathrm{GH}$ deficiency ( $\mathrm{GH}$ peak $<3 \mathrm{ng} / \mathrm{ml}$ ) confirmed by hypoglycemic provocation tests and ii) anterior pituitary hypoplasia as detected by a brain magnetic resonance imaging (MRI). Of the 88 patients, 30 were syndromic $(\mathrm{CH}$ with extra-pituitary abnormalities such as midline defects, intellectual disability, and cardiac defects), whereas 58 were non-syndromic. The details of 30 syndromic patients are summarized in Table 1 . In all the patients, mutations in POU1F1, PROP1, HESX1, LHX3, LHX4, OTX2, SOX2, SOX3, and GLI2 have been excluded by PCR-based sequencing (4). Gene copy number aberrations in POU1F1, PROP1, HESX1, LHX3, and LHX4 were also excluded by multiplex ligation-dependent probe amplification (MLPA) analyses (4). Approval for this study was obtained from the Institutional Review Board of Keio University School of Medicine. We obtained written informed consent for molecular studies from the patient or the patient's parents.

\section{Endocrinological investigations}

Hormonal assays were performed using several commercial RIA kits, and normal values for each center were taken into account. The results of biochemical investigations at diagnosis were recorded including basal free thyroxine ( $\left.\mathrm{fT}_{4}\right)$, thyroid-stimulating hormone (TSH), cortisol, adrenocorticotropin (ACTH) levels, and their peaks in response to pituitary stimulation tests. The patients were evaluated for serum GH level after two consecutive classical provocative tests (with arginine or insulin). GH peaks, $6 \mathrm{ng} / \mathrm{ml}$ after stimuli, support a diagnosis of GHD. GH peaks, $3 \mathrm{ng} / \mathrm{ml}$ by hypoglycemic provocation test, define severe GHD. A diagnosis of TSH deficiency was made if serum $\mathrm{fT}_{4}$ concentration was under the normal level ( $\mathrm{fT}_{4}, 1.0 \mathrm{ng} / \mathrm{dl}$ ) with inadequate low to normal serum TSH concentration. Cortisol peaks, $17 \mathrm{mg} / \mathrm{dl}$ by hypoglycemic provocation tests, define ACTH deficiency. Folliclestimulating hormone (FSH)-luteinizing hormone (LH) deficiency was diagnosed on the basis of delayed or absent pubertal development at the age of 16 years and inadequate increase in serum FSH and LH in response to LH-releasing hormone.

Of the 88 patients, on the basis of hormonal deficiencies, 13 were determined to have IGHD, whereas 75 had MPHD (Supplementary Table 1, see section on supplementary data given at the end of this article).

\section{Imaging investigations}

MRI included T1 and T2-weighted, high-resolution pituitary imaging through the hypothalamo-pituitary-axis (T1 sagittal 3-mm slices, T1 and T2 coronal 3-mm slices). Details noted included the size of the anterior pituitary, position of the posterior pituitary signal, presence and morphology of the optic nerves, optic chiasm, pituitary stalk, septum pellucidum, and corpus callosum.

Results of the MRI scans were available in all patients with IGHD and MPHD. Details regarding the structural abnormalities of the hypothalamo-pituitary-axis on neuroimaging in the probands are given in Supplementary Table 2 , see section on supplementary data given at the end of this article.

\section{Comparative genomic hybridization array screening}

We performed an array-comparative genomic hybridization (CGH) screening in 30 syndromic $\mathrm{CH}$ patients, whose karyotypes were confirmed to be normal by G-banding. CGH was performed using the Agilent SurePrint G3 Human CGH Microarray kit, $4 \times 180$ K, $13 \mathrm{~kb}$ spatial resolution, or $1 \times 1 \mathrm{M}, 2.1 \mathrm{~kb}$ spatial resolution (Agilent Technologies, Santa Clara, CA, USA), according to the manufacturer's protocol. 
Table 1 The details of 30 syndromic patients.

\begin{tabular}{|c|c|c|c|c|c|}
\hline Patient ID & Age (years) & Sex & $\begin{array}{l}\text { Affected pituitary } \\
\text { hormones }\end{array}$ & MRI findings & $\begin{array}{l}\text { Clinical findings } \\
\text { (extra-pituitary abnormalities) }\end{array}$ \\
\hline 1 (pedigree 1) & 6 & $\mathrm{M}$ & $\mathrm{GH}$ & APH, EPP, TS & Cleft palate, optic disk cupping \\
\hline 2 (pedigree 2) & 6 & $\mathrm{M}$ & GH, TSH & APH, EPP, TS & $\begin{array}{l}\text { Bilateral anophthalmia, PDA, } \\
\text { dysmorphic face, MR }\end{array}$ \\
\hline 3 & 15 & $\mathrm{~F}$ & $\mathrm{GH}, \mathrm{ACTH}$ & APH, NPP, TS & SOD $(\mathrm{ONH}+\mathrm{APH})$ \\
\hline 4 & 20 & $\mathrm{M}$ & GH, TSH & APH, NPP, ACC, IS & $\mathrm{SOD}(\mathrm{ONH}+\mathrm{APH}+\mathrm{ACC})$ \\
\hline 5 & 28 & $\mathrm{M}$ & $\mathrm{GH}, \mathrm{TSH}, \mathrm{ACTH}$ & APH, EPP, IS & Cleft palate, MR \\
\hline 6 & 18 & $\mathrm{M}$ & $\mathrm{GH}$ & APH, EPP, IS & $\mathrm{MR}$ \\
\hline 7 & 14 & $\mathrm{~F}$ & $\mathrm{GH}$ & $\mathrm{APH}, \mathrm{EPP}, \mathrm{ASP}, \mathrm{TS}$ & $\mathrm{SOD}(\mathrm{ONH}+\mathrm{APH}+\mathrm{ASP})$ \\
\hline 8 & 8 & $\mathrm{M}$ & $\mathrm{GH}, \mathrm{TSH}$ & APH, EPP, ASP, TS & $\mathrm{SOD}(\mathrm{ONH}+\mathrm{APH}+\mathrm{ASP})$ \\
\hline 9 & 10 & $\mathrm{~F}$ & $\mathrm{GH}$ & $\mathrm{APH}, \mathrm{NPP}, \mathrm{TS}$ & SOD $(\mathrm{ONH}+\mathrm{APH})$ \\
\hline 10 & 5 & $\mathrm{~F}$ & $\mathrm{GH}, \mathrm{TSH}, \mathrm{ACTH}$ & APH, NPP, IS & $\begin{array}{l}\text { Congenital absence of the scalp, } \\
\text { ear anomaly }\end{array}$ \\
\hline 11 & 24 & $\mathrm{~F}$ & GH, LH/FSH & APH, NPP, NS & Hearing impairment, PDA \\
\hline 12 & 8 & $\mathrm{M}$ & $\mathrm{GH}$ & APH, NPP, NS & Cleft palate \\
\hline 13 & 16 & $\mathrm{~F}$ & $\mathrm{GH}$ & APH, NPP, IS & Cleft palate, hearing impairment \\
\hline 14 & 5 & $\mathrm{~F}$ & $\mathrm{GH}, \mathrm{TSH}, \mathrm{ACTH}$ & APH, EPP, IS & $\mathrm{SOD}(\mathrm{ONH}+\mathrm{APH})$ \\
\hline 15 & 4 & $\mathrm{M}$ & GH & APH, EPP, IS & $\mathrm{SOD}(\mathrm{ONH}+\mathrm{APH})$ \\
\hline 16 & 7 & $\mathrm{M}$ & $\mathrm{GH}, \mathrm{TSH}$ & APH, EPP, IS & Dysmorphic face, MR \\
\hline 17 & 9 & $\mathrm{M}$ & $\mathrm{GH}, \mathrm{TSH}, \mathrm{ACTH}$ & APH, EPP, TS & Cleft palate, VSD \\
\hline 18 & 10 & $\mathrm{~F}$ & $\mathrm{GH}, \mathrm{ACTH}$ & $\mathrm{APH}, \mathrm{EPP}, \mathrm{ACC}, \mathrm{TS}$ & $\mathrm{SOD}(\mathrm{ONH}+\mathrm{APH}+\mathrm{ACC})$ \\
\hline 19 & 14 & $\mathrm{M}$ & GH, TSH & APH, EPP, ASP, TS & SOD $(\mathrm{ONH}+\mathrm{APH}+\mathrm{ASP})$ \\
\hline 20 & 3 & $\mathrm{M}$ & $\mathrm{GH}, \mathrm{TSH}, \mathrm{ACTH}$ & APH, EPP, IS & SOD (ONH+APH) \\
\hline 21 & 8 & $\mathrm{M}$ & $\mathrm{GH}, \mathrm{TSH}$ & $\mathrm{APH}, \mathrm{EPP}, \mathrm{ACC}, \mathrm{IS}$ & $\mathrm{SOD}(\mathrm{ONH}+\mathrm{APH}+\mathrm{ACC})$ \\
\hline 22 & 8 & $\mathrm{M}$ & $\mathrm{GH}, \mathrm{TSH}, \mathrm{ACTH}$ & APH, EPP, IS & SOD (ONH+APH) \\
\hline 23 & 19 & $\mathrm{~F}$ & GH, TSH & APH, EPP, IS & SOD $(\mathrm{ONH}+\mathrm{APH})$ \\
\hline 24 & 14 & $\mathrm{M}$ & $\mathrm{GH}, \mathrm{TSH}$ & APH, NPP, NS & Cleft palate \\
\hline 25 & 10 & $\mathrm{~F}$ & $\mathrm{GH}, \mathrm{TSH}$ & APH, EPP, ACC, IS & $\mathrm{SOD}(\mathrm{ONH}+\mathrm{APH}+\mathrm{ACC})$ \\
\hline 26 & 11 & $\mathrm{~F}$ & $\mathrm{GH}, \mathrm{TSH}, \mathrm{ACTH}$ & APH, NPP, IS & Cleft palate, PDA \\
\hline 27 & 23 & $\mathrm{~F}$ & $\mathrm{GH}, \mathrm{LH} / \mathrm{FSH}$ & APH, NPP, NS & Morning glory syndrome \\
\hline 28 & 3 & $\mathrm{M}$ & $\mathrm{GH}, \mathrm{TSH}$ & APH, EPP, IS & $\mathrm{SOD}(\mathrm{ONH}+\mathrm{APH})$ \\
\hline 29 & 6 & $\mathrm{M}$ & GH, TSH, ACTH & APH, EPP, IS & $\mathrm{SOD}(\mathrm{ONH}+\mathrm{APH})$ \\
\hline 30 & 20 & $\mathrm{M}$ & GH, TSH, ACTH, LH/FSH & $\mathrm{APH}, \mathrm{EPP}, \mathrm{IS}$ & $\begin{array}{l}\text { Hearing impairment, right } \\
\text { microphthalmia, MR }\end{array}$ \\
\hline
\end{tabular}

ACC, agenesis of the corpus callosum; APH, anterior pituitary hypoplasia; ASP, absence of septum pellucidum; EPP, ectopic posterior pituitary; $\mathrm{F}$, female; IS, invisible stalk; M, male; MR, mental retardation; NPP, normal posterior pituitary; NS, normal stalk; ONH, optic nerve hypoplasia; PDA, patent ductus arteriosus; SOD, septo-optic dysplasia; TS, thin stalk; VSD, ventriculoseptal defect.

\section{PAX6 mutation screening}

For all the 88 patients, we analyzed all coding exons and flanking introns of PAX6 by PCR-based sequencing. For detailed protein sequence information, see EMBL database accession numbers ENSP00000368418 (PAX6). We screened for deletion/duplication involving PAX6 by MLPA analyses (SALSA MLPA KIT P219; MRC-Holland, Amsterdam, The Netherlands). We tested for any detected sequence variations against 150 Japanese control subjects.

\section{Functional studies on the novel PAX6 mutation (p.N116S)}

The details of the experimental procedures are described in Supplementary methods, see section on supplementary data given at the end of this article. In brief, PAX6 cDNA was cloned into pCMV-myc and pEGFP-N1 (Clontech) to generate PAX6 expression vectors. We introduced the mutation by site-directed mutagenesis using the Prime STAR Mutagenesis Basal kit (TaKaRa, Otsu, Japan). The primer pairs, forward (F) and reverse (R), used for mutagenesis were as follows: N116S (F)-5'-AACGATAGCATACCAAGCGTGTCATCAA-3', N116S (R)-5' -TGGTATGCTATCGTTGGTACAGACCC-3'. Transactivation assay was performed using P6CON luciferase reporter vector, which was constructed by inserting the six copies of PAX6 consensus binding elements, and dual-luciferase reporter assay system (Promega) on COS1 and GH3 cells. For subcellular localization analyses, we visualized and photographed COS1 cells transfected with GFP-tagged PAX6. For western blotting analyses, we harvested COS1 cells 
transfected with the myc-tagged PAX6. Western blotting analysis was performed using a mouse anti-myc MAB (Invitrogen). EMSA experiment was performed using the Lightshift chemiluminescent EMSA kit (Pierce, Rockford, IL, USA) according to the manufacturer's instructions.

\section{Crystal structure modeling}

The crystal structure of the PAX6 paired domain (protein data bank ID 6PAX; http://www.rcsb.org/pdb/) was used as a reference WT structure for modeling the structure of p.N116S PAX6 by using the PyMOL Molecular Graphics System (http://www.pymol.org).

\section{Results}

\section{CGH array screening}

Among the 30 syndromic $\mathrm{CH}$ patients, we identified one heterozygous deletion, which was of estimated minimum extent $308 \mathrm{~kb}$, extending from bp 31474276 to bp 31783119 on chromosome 11q13 (NCBI Build 37/hg 19) (Fig. 1A). Maximum size was $311 \mathrm{~kb}$, from bp 31471923 to bp 31785385 . The deletion included two genes (ELP4 and IMMP1L) and PAX6 putative enhancer region, with the coding region of $P A X 6$ being unaffected, in one patient with IGHD, cleft palate, and optic disc cupping. The deletion of the PAX6 putative enhancer, or other deletions encompassing the one we identified, was not registered as frequent, non-pathogenic CNVs in existing database, including the database of genomic variants, DECIPHER, and UCSC. To confirm the deletion, fluorescence in situ hybridization (FISH) was performed on the metaphase slides from peripheral blood lymphocytes using the RP11-151O13 clones (Fig. 1A). Parental analysis revealed that the clinically normal father possessed the deletion in somatic mosaicism (number of cells with PAX6 haploinsufficiency was eight, out of 20 counted cells), confirmed by FISH, whereas the mother did not. Second, we also identified one heterozygous $6.5-\mathrm{Mb}$ deletion encompassing OTX2 (Fig. 1B) in a MPHD patient with bilateral anophthalmia, dysmorphic facies, severe developmental delay, and a patent ductus arteriosus. No other syndromic $\mathrm{CH}$ patients had pathological CNVs.

\section{PAX6 mutation screening}

We identified one novel heterozygous PAX6 mutation, namely p.N116S (Fig. 1C). The p.N116 in PAX6 is an evolutionarily highly conserved amino acid located in the
(A)

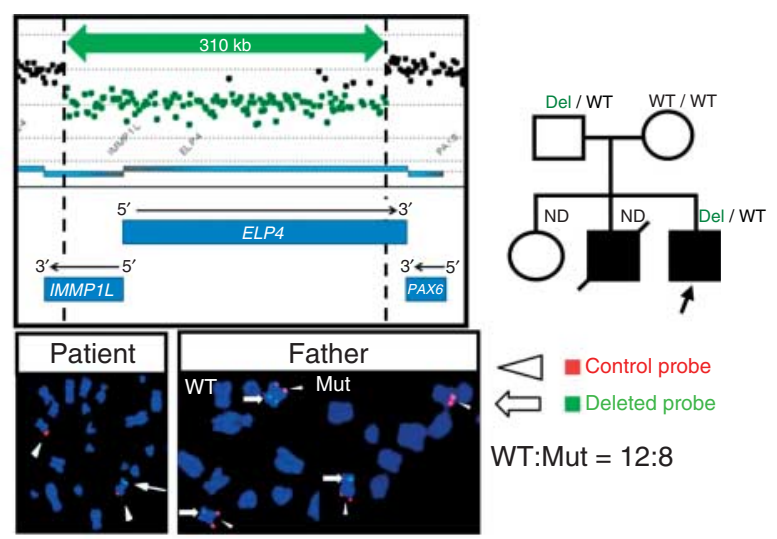

(B)
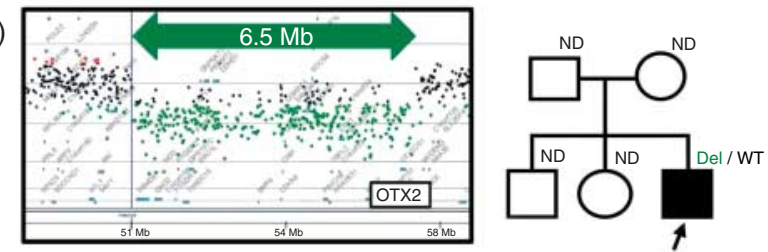

(C)
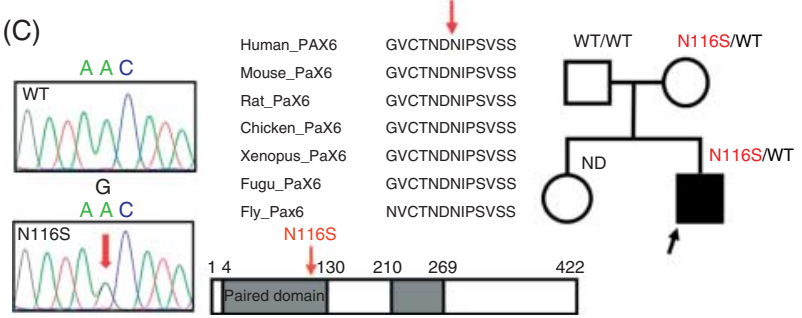

\section{Figure 1}

Identification of deletions and sequence variation.

(A) Graphical representation of the results of the array CGH analysis (Agilent $1 \times 1 \mathrm{M}$ SurePrint G3 Human CGH Microarray) shows one heterozygous 310-kb deletion of PAX6 putative enhancer region, including two neighboring genes: ELP4, and IMMP1L, with the coding region of PAX6 being unaffected. The pedigree of this family is shown in the right side. Arrow indicates the propositus. The deletion was confirmed by FISH, using the RP11-151013 clones. The clinically normal father possessed the deletion in somatic mosaicism (number of cells with PAX6 haploinsufficiency was eight, out of 20 counted cells).

(B) Graphical representation of the results of the array CGH analysis (Agilent $4 \times 180 \mathrm{~K}$ SurePrint G3 Human CGH Microarray) shows one heterozygous $6.5-\mathrm{Mb}$ deletion encompassing OTX2. The pedigree of this family is shown in the right side. Arrow indicates the propositus. (C) Partial sequences of PCR products of the patients are shown, and the chromatogram represents a heterozygous substitution of serine (AGC) in place of asparagine (AAC) at codon 116. Asn 116 is highly conserved through species, and is located within the paired domain. Genetic analyses showed that the propositus and his clinically normal mother carried the same heterozygous PAX6 p.N116S mutation. 
paired domain (Fig. 1C). The p.N116S was not detected in any of the 150 healthy controls and was absent from extant database, including dbSNP, the 1000 Genomes Project, Exome Variant Server, and NHLBI Exome Sequencing Project. We detected no gross or exon-level deletions/ duplications on performing the MLPA analyses.

\section{Clinical phenotypes of the mutation carriers}

Pedigree 1: PAX6 enhancer deletion $\downarrow$ The propositus was a 6-year-old Japanese boy, who was born at 37 weeks of gestation after an uncomplicated pregnancy and delivery (Fig. 1A). At birth, his length was $48.0 \mathrm{~cm}$ ( -0.5 s.D.) and weight $2.98 \mathrm{~kg}$ ( -0.1 S.D.). He had cleft palate that was surgically repaired. He was referred to us at 3 years of age because of his short stature. His height was $85.2 \mathrm{~cm}$ ( -3.0 s.D.). Endocrine studies indicated that he had IGHD (Supplementary Table 3, see section on supplementary data given at the end of this article). A brain MRI showed anterior pituitary hypoplasia, with a visible but thin stalk, and an ectopic posterior pituitary gland (EPP) (Fig. 2A). No other CNS abnormalities were visualized. Recombinant human GH therapy was started at an age of 3 years. He responded well to GH $(0.175 \mathrm{mg} / \mathrm{kg}$ per week) replacement therapy. Examination by experienced ophthalmologists revealed a bilateral optic disc cupping. His father was $173.0 \mathrm{~cm}$ (0.4 S.D.) tall, and his mother was $153.0 \mathrm{~cm}$ $(-1.0$ s.D.) tall. His older brother was diagnosed to have holoprosencephaly by a brain MRI (Fig. 2B), and he died at the age of 1 year. The older sister did not have a short stature. Hormonal data of the father, harboring the deletion in somatic mosaicism, was not evaluated.

Pedigree 2: OTX2 deletion $>$ The propositus was a 6-yearold Japanese boy, who was born at 40 weeks of gestation after an uncomplicated pregnancy and delivery (Fig. 1B). The patient was the third child of non-consanguineous healthy parents. His older brother and sister were clinically normal. At birth, his length was $51.0 \mathrm{~cm}(1.0$ S.D.) and weight $3.05 \mathrm{~kg}$ (0.1 s.D.). A constellation of malformations was noticed, including bilateral anophthalmia, and small and uplifted earlobes with very small external auditory canals. The testes were undescended, the scrotum small, and the foreskin hypoplastic. Echocardiogram revealed a patent ductus arteriosus, which was surgically corrected at 1 month of age. At the age of 1 year, he was diagnosed with central hypothyroidism with a low $\mathrm{fT}_{4}(0.44 \mathrm{ng} / \mathrm{dl}$ : ref. 0.99-1.91) and an inadequately increased TSH level of $11.58 \mathrm{mU} / \mathrm{l}$. Further endocrine studies indicated that the patient also had
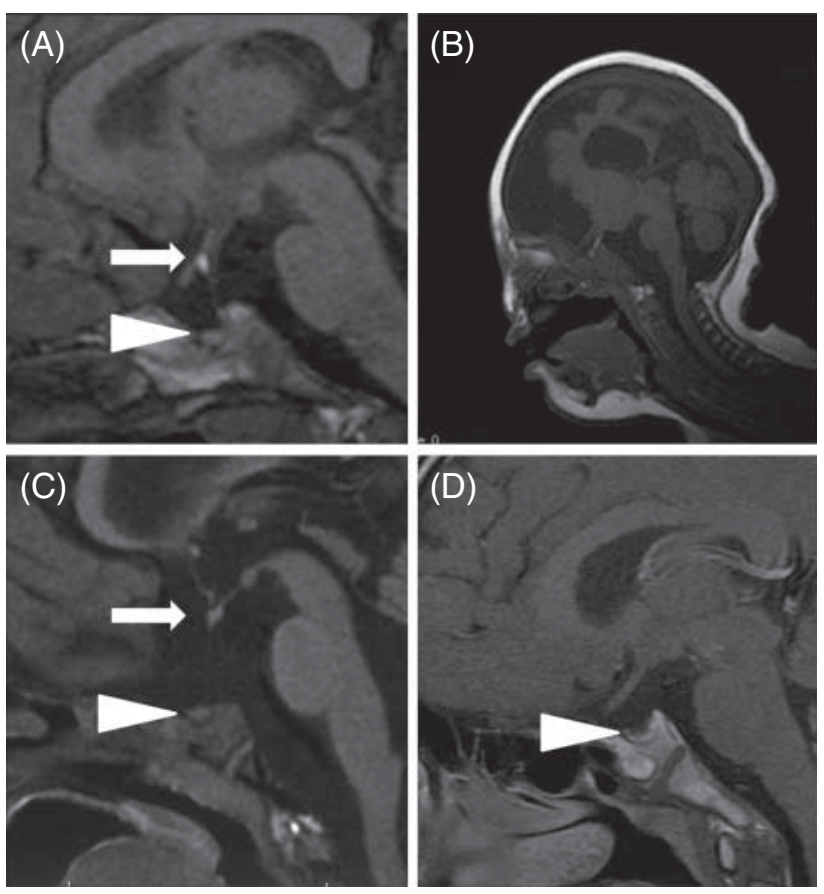

\section{Figure 2}

Pituitary structures on T1-weighted MRI scans of patients in pedigrees 1-3. Arrows indicate ectopic posterior pituitary and arrow heads indicate anterior pituitary hypoplasia. (A and $B$ ) Propositus in pedigree $1(A)$ and his elder brother, who was diagnosed as holoprosencephaly (B), (C) propositus in pedigree 2 , and (D) propositus in pedigree 3.

GHD (Supplementary Table 4, see section on supplementary data given at the end of this article). The brain MRI exhibited anterior pituitary hypoplasia, visible but thin stalk, and EPP (Fig. 2C). Replacement therapy with thyroxine and recombinant human GH was started at the ages of 1 and 3 years respectively. No other family members were available for genetic studies or evaluation of hormonal data.

Pedigree 3: PAX6 p.N116S The propositus was a 15-year-old Japanese male, who was born at 40 weeks of gestation after an uncomplicated pregnancy and delivery (Fig. 1C). At birth, his length was $44.0 \mathrm{~cm}(-2.4$ s.D.) and weight $2.67 \mathrm{~kg}$ ( -0.8 s.D.). He was referred to us at the age of 3 years because of short stature and bilateral cryptorchidism. His hormonal data revealed IGHD (Supplementary Table 5, see section on supplementary data given at the end of this article). A brain MRI exhibited anterior pituitary hypoplasia, visible but thin 
stalk, poorly developed sella turcica, and eutopic posterior pituitary (Fig. 2D). He showed no ocular malformation. Replacement therapy with recombinant human GH was started at the age of 4 years. The patient responded well to $\mathrm{GH}$ replacement therapy. At the age of 15 years, he showed no pubic hair; his penile length was $9 \mathrm{~cm}$, and his testicular volume was $6 \mathrm{ml}$ bilaterally, with normal concentration of basal testosterone $(3.98 \mathrm{ng} / \mathrm{ml}$ ref: 2.0-7.5). The results of his gonadotropin-releasing hormone and human chorionic gonadotropin test were normal (Supplementary Table 5). His father was $170.0 \mathrm{~cm}$ ( -0.1 s.D.) tall, and mother was $158.0 \mathrm{~cm}$ (0.1 s.D.) tall. Genetic analyses showed that the propositus and his mother carried the same heterozygous PAX6
p.N116S mutation. Hormonal data of the mother were normal (Supplementary Table 6, see section on supplementary data given at the end of this article).

\section{Functional studies}

Both in COS1 and GH3 cells, WT PAX6 stimulated the transcription of the $\mathrm{P} 6 \mathrm{CON}$ reporter in a dose-dependent manner. The p.N116S retained partial activity without any dominant negative effect (Fig. 3A). The p.N116S mutant localized to the nucleus (Fig. 3B). The western blot analysis showed that the expression of the p.N116S was comparable with that of the WT (Fig. 3C). The WT PAX6 showed specific binding to the oligonucleotide elements,
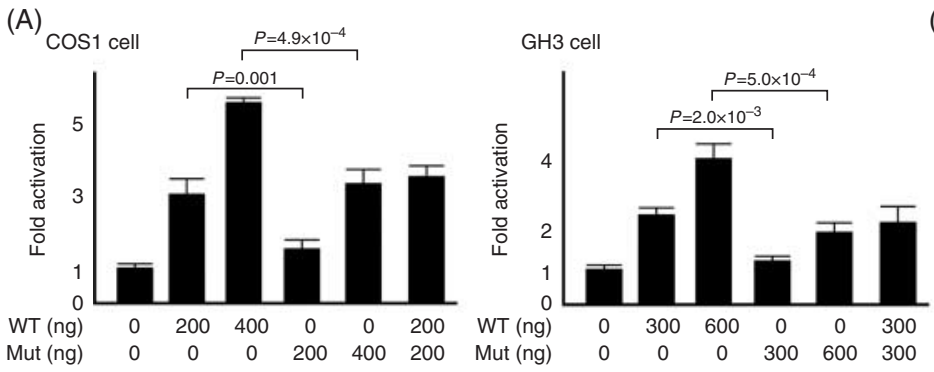

(C)

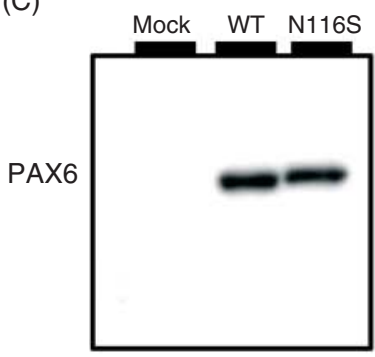

(D)

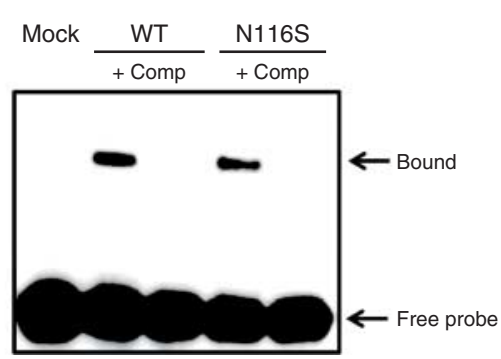

(B)

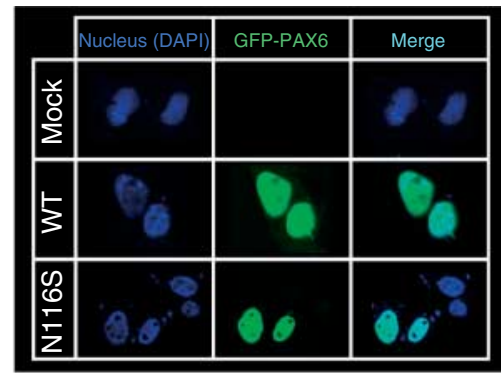

(E)

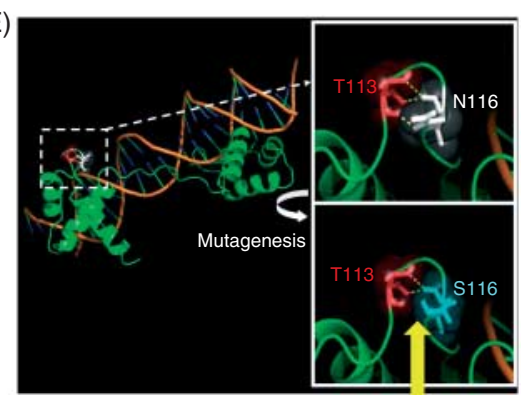

\section{Figure 3}

Functional characterization and modeled structure of N116S PAX6. (A) Transactivation assays of the p.N116S PAX6 using $\mathrm{P} 6 \mathrm{CON}$ reporter in COS1 and GH3 cells. COS1 or GH3 cells were cotransfected with the $\mathrm{pRL}-\mathrm{CMV}$ internal control vector, indicated amount (nanograms) of the effector plasmids, and the P6CON reporter. The data are the mean \pm s.E.M. of at least three independent experiments performed in triplicate transfections. The p.N116S PAX6 retained partial activity and did not exhibit any dominant negative effect. (B) Subcellular localization analysis. For subcellular localization analyses, we visualized and photographed COS1 cells transfected with GFP-tagged PAX6 using a Leica TCS-SP5 laser scanning confocal microscope, after mounting the cells in Vectashield-DAPI solution. The WT and p.N116S PAX6 are localized to the nucleus. (C) Western blotting analysis. Western blotting analysis showed that the expression of p.N116S PAX6 was comparable with that of the WT. (D) EMSA experiments. WT PAX6 showed specific binding to the elements, which was competed by excess amount (200 times) of cold competitors. The p.N116S PAX6, which has an intact HD, bound with similar efficiency to the WT PAX6. (E) Modeled structure of the p.N116S PAX6 in comparison with the WT structure (upper panels). Modeling of mutant was performed using a built-in mutagenesis function of the PyMOL Molecular Graphics System. Crystal structural modeling showed that the p.N116S PAX6 was predicted to lose the hydrogen bond between N116 and T113 (arrow). 
which was competed for by an excess amount of cold competitors (200 times). The p.N116S bound with similar efficiency to the WT PAX6 (Fig. 3D).

\section{Crystal structure modeling}

The p.N116S was predicted to lose the hydrogen bond between N116 and T113 (Fig. 3E).

\section{Discussion}

This study describes the first series of $\mathrm{CH}$ patients to be screened for chromosomal rearrangements with highresolution oligonucleotide microarrays. Overall, this study identified two different CNVs with a possible role in the etiology of $\mathrm{CH}$ in two patients among 30 syndromic $\mathrm{CH}$ patients (6.6\%). Thus, the causes of $\mathrm{CH}$ remain elusive in most patients, and further studies are required to understand the pathogenesis of $\mathrm{CH}$.

PAX6 is a well-known regulator of eye development, and its heterozygous mutations in humans cause congenital eye anomalies such as aniridia, foveal hypoplasia, optic-nerve malformations, and Peters' anomaly. Kioussi et al. (9) showed that PAX6 is an early dorsal marker of early anterior pituitary gland, and its expression controls the established boundaries of somatotrope, lactotrope, and thyrotrope cell types. Dorsal expression of PAX6 is essential for establishing a sharp boundary between dorsal and ventral cell types, and the absence of PAX6 leads to a marked increase in the thyrotrope cell lineage, whereas the somatotrope and lactotrope cell lineage changes are very much diminished (9). These data strongly support our findings that PAX6 mutations are associated with $\mathrm{CH}$.

Recently two papers have been published, showing that PAX6 mutations may be associated with impaired pituitary function $(10,11)$. Hergott et al. reported data on detailed pituitary studies using the stimulation testing of five PAX6 mutation carriers (10). In this paper, they found no clear pituitary deficiencies other than subtle corticotrope deficiency. Shimo et al. (11) reported one case of PAX6 mutation with subtle hypogonadotropic hypogonadism and borderline GH deficiency. However, this particular case is unconvincing because the subject was obese (which blunts GH response to GH stimulation testing), had normal adult stature of $165 \mathrm{~cm}$, normal menses and pregnancies. Therefore, we showed, for the first time, that heterozygous PAX6 mutations are associated with definite $\mathrm{CH}$ patients with or without ocular malformation, and the frequency of PAX6 mutations in $\mathrm{CH}$ was $2.3 \%$. To date, more than 350 mutations or variants in PAX6 have been reported (12), and almost all were found in the heterozygous state. Although extremely rare, at least four patients harboring biallelic mutations in PAX6 have been reported $(13,14,15)$. Three patients were stillborn or died in early infancy with severe CNS anomalies, but one long surviving patient among them showed MPHD and anterior pituitary hypoplasia (13), further supporting a role for PAX6 in the pituitary development in human.

In pedigree 1 , we identified a heterozygous $310 \mathrm{~kb}$ deletion of the downstream flanking region of PAX 6 in an IGHD patient with cleft palate and bilateral optic disc cupping. The known control that PAX6 exerts over the temporospatial expression of Sonic hedhehog $(\mathrm{SHH})(16)$, the critical importance of $P A X 6$ on pituitary development through SHH (9), and the critical importance of $S H H$ on palate development (17) strongly support the argument for PAX6 defects being pathogenic events responsible for the phenotype. Previously, several authors described submicroscopic deletions downstream of PAX6, with the coding region of PAX6 being unaffected $(18,19,20$, 21, 22). Davis et al. (18) identified a $1.3 \mathrm{Mb}$ deletion, including six neighboring genes: ELP4, DPH4, DCDC1, DCDC5, MPPED2, and IMMP1L, localized $\sim 35 \mathrm{~kb}$ downstream of PAX6 in a patient with aniridia, autism, and intellectual disability. Analysis of the region with a breakpoint located $124 \mathrm{~kb}$ downstream of the PAX6 polyadenylation site using YAC transgenic mice, DNase I hypersensitivity mapping and reporter transgenic assays, showed the presence of several cis-regulatory elements, including a lens-specific and a retina-specific element. These elements are located within the introns of the ELP4 gene and are $P A X 6$-specific long-range control elements $(22,23)$. ELP4, which is ubiquitous but with variable expression in human tissues, acts as subunit of the RNA polymerase II elongator complex, which is a histone acetyltransferase component of the RNA polymerase II holoenzyme and is involved in transcriptional elongation (24). IMMP1L, which is located at the mitochondrion inner membrane, catalyzes the removal of transit peptides required for the targeting of proteins from the mitochondrial matrix across the inner membrane into the inter-membrane space (25). The deletion, we identified, includes ELP4 and IMMP1L. While deletions in the ELP4 gene have been shown to suppress PAX6 gene expression and cause aniridia (19), implications of IMMP1L in the described phenotype are not clear. Although pituitaryspecific elements are not well studied, we believe that our findings will shed light on the role for PAX6 in the pituitary development in humans. 
Wide phenotypic spectrum in PAX6 mutation carriers is noteworthy. In pedigree 1, the proband's older brother was diagnosed to have holoprosencephaly, the most common forebrain developmental anomaly in humans. Unfortunately gene analysis data for the brother were not available. However, the mosaicism of the deletion in his father strongly suggested that the most severe phenotype was due to the same deletion and the variable penetrance of PAX6 mutations. Of course, the effect of environmental factors, second hit in PAX6, or mutation in other genes for holoprosencephaly, was not excluded. In pedigree 3, the patient's mother was of normal adult height and had normal baseline hormonal levels. The p.N116S was associated with impaired transactivation without dominant-negative effects, indicating haploinsufficiency. The western blotting analysis, visualization of subcellular localization, and a DNA-binding test revealed no significant difference between the WT and p.N116S PAX6. Asn 116 is a highly conserved amino acid located in the paired domain, suggesting that substitution of Asn 116 to Ser, which is predicted to lose the hydrogen bond between N116 and T113, results in defective interactions with transcriptional cofactors. PAX6 mutations may be associated with diverse clinical features ranging from severely impaired ocular and pituitary development to apparently normal phenotype. PAX genes may be sometimes monoallelicaly expressed and the individual factors governing such monoalleic expression are not understood. Since the found mutation is heterozygous, theoretically a favorable monoallelic expression from the correct allele in the mother might cause the lack of phenotype, and the expression from the mutated allele in the patient might cause the phenotype $(26,27,28)$. The phenotypical variation within the same pedigree could also be partly due to the impact of other genes that are important but have not been recognized in pituitary development. Of course, the possibility that p.N116S PAX6 could have no significance in vivo effect in human, and that he had a de novo mutation in some other yet-to-be- identified gene causative for $\mathrm{CH}$, should also be considered.

In summary, we showed, for the first time, that heterozygous PAX6 mutations are associated with definite $\mathrm{CH}$ patients with or without ocular malformation. The frequency of PAX6 mutations in $\mathrm{CH}$ was $2.3 \%$. PAX6 mutations may be associated with diverse clinical features ranging from severely impaired ocular and pituitary development to apparently normal phenotype. Overall, this study identified causative CNVs with a possible role in $\mathrm{CH}$ in $<10 \%$ of the syndromic $\mathrm{CH}$ patients.

\section{Supplementary data}

This is linked to the online version of the paper at http://dx.doi.org/10.1530/ EJE-14-0255.

Declaration of interest

The authors declare that there is no conflict of interest that could be perceived as prejudicing the impartiality of the research reported.

\section{Funding}

This work was supported by Grants from the Japan Society for the Promotion of Science (Grant-in-Aid for Young Scientists (B) (25860900)), Health and Labour Sciences Research Grant for Research on Applying Health Technology (Jitsuyoka (Nanbyo) - Ippan-014), and was partly supported by a grant from the Foundation for Growth Science, Japan.

\section{Author contribution statement}

M Takagi and T Hasegawa conceived and designed the experiments, M Takagi performed the experiments, M Takagi analyzed the data: K Nagasaki, I Fujiwara, T Ishii, N Amano, Y Asakura, K Muroya, Y Hasegawa, $M$ Adachi contributed for reagents/materials/analysis tools, and M Takagi and T Hasegawa wrote the paper.

\section{Acknowledgements}

The authors thank $\mathrm{Dr} \mathrm{H}$ Nishina (Department of Developmental and Regenerative Biology, Medical Research Institute, Tokyo, Japan) for P6CONluc reporter construct. They also thank Prof. Takao Takahashi for fruitful discussion.

\section{References}

1 Romero CJ, Nesi-França S \& Radovick S. The molecular basis of hypopituitarism. Trends in Endocrinology and Metabolism 200920 506-516. (doi:10.1016/j.tem.2009.06.005)

2 Kelberman D, Rizzoti K, Lovell-Badge R, Robinson IC \& Dattani MT. Genetic regulation of pituitary gland development in human and mouse. Endocrine Reviews 200930 790-829. (doi:10.1210/er.2009-0008)

3 Pfäffle R \& Klammt J. Pituitary transcription factors in the aetiology of combined pituitary hormone deficiency. Best Practice \& Research. Clinical Endocrinology \& Metabolism 201125 43-60. (doi:10.1016/j. beem.2010.10.014)

4 Takagi M, Ishii T, Inokuchi M, Amano N, Narumi S, Asakura Y, Muroya K, Hasegawa Y, Adachi M \& Hasegawa T. Gradual loss of ACTH due to a novel mutation in LHX4: comprehensive mutation screening in Japanese patients with congenital hypopituitarism. PLoS ONE 20127 e46008. (doi:10.1371/journal.pone.0046008)

5 Reynaud R, Gueydan M, Saveanu A, Vallette-Kasic S, Enjalbert A, Brue T $\&$ Barlier A. Genetic screening of combined pituitary hormone deficiency: experience in 195 patients. Journal of Clinical Endocrinology and Metabolism 200691 3329-3336. (doi:10.1210/jc.2005-2173)

6 Williams PG, Wetherbee JJ, Rosenfeld JA \& Hersh JH. 20p11 deletion in a female child with panhypopituitarism, cleft lip and palate, dysmorphic facial features, global developmental delay and seizure disorder. American Journal of Medical Genetics. Part A 2011 155A 186-191. (doi:10.1002/ajmg.a.33763) 
7 Garcia-Heras J, Kilani RA, Martin RA \& Lamp S. A deletion of proximal 20p inherited from a normal mosaic carrier mother in a newborn with panhypopituitarism and craniofacial dysmorphism. Clinical Dysmorphology 200514 137-140. (doi:10.1097/00019605-200507000-00006)

8 Brunetti-Pierri N, Patel A, Brown CW, Rauch RA \& Heptulla RA. De novo terminal 22q12.3q13.3 duplication with pituitary hypoplasia. American Journal of Medical Genetics. Part A 2009 149A 2554-2556. (doi:10.1002/ ajmg.a.33041)

9 Kioussi C, O'Connell S, St-Onge L, Treier M, Gleiberman AS, Gruss P \& Rosenfeld MG. Pax6 is essential for establishing ventral-dorsal cell boundaries in pituitary gland development. PNAS 199996 14378-14382. (doi:10.1073/pnas.96.25.14378)

10 Hergott-Faure L, Borot S, Kleinclauss C, Abitbol M \& Penfornis A. Pituitary function and glucose tolerance in a family with a PAX6 mutation. Annales d'Endocrinologie 201273 510-514. (doi:10.1016/ j.ando.2012.10.001)

11 Shimo N, Yasuda T, Kitamura T, Matsushita K, Osawa S, Yamamoto Y, Kozawa J, Otsuki M, Funahashi T, Imagawa A et al. Aniridia with a heterozygous PAX6 mutation in which the pituitary function was partially impaired. Internal Medicine 201453 139-142. (doi:10.2169/ internalmedicine.53.1184)

12 Leiden University Medical Center. Leiden Open Variation Database. MRC Human Genetics Unit LOVD at MRC IGMM. Leiden University Medical Center web site. http://lsdb.hgu.mrc.ac.uk/home.php.

13 Solomon BD, Pineda-Alvarez DE, Balog JZ, Hadley D, Gropman AL, Nandagopal R, Han JC, Hahn JS, Blain D, Brooks B et al. Compound heterozygosity for mutations in PAX6 in a patient with complex brain anomaly, neonatal diabetes mellitus, and microophthalmia. American Journal of Medical Genetics. Part A 2009 149A 2543-2546. (doi:10.1002/ ajmg.a.33081)

14 Glaser T, Jepeal L, Edwards JG, Young SR, Favor J \& Maas RL. PAX6 gene dosage effect in a family with congenital cataracts, aniridia, anophthalmia and central nervous system defects. Nature Genetics 1994 7 463-471. (doi:10.1038/ng0894-463)

15 Schmidt-Sidor B, Szymańska K, Williamson K, van Heyningen V, Roszkowski T, Wierzba-Bobrowicz T \& Zaremba J. Malformations of the brain in two fetuses with a compound heterozygosity for two PAX6 mutations folia. Neuropathology 200947 372-382.

16 Chatterjee M, Guo Q, Weber S, Scholpp S \& Li JY. Pax6 regulates the formation of the habenular nuclei by controlling the temporospatial expression of Shh in the diencephalon in vertebrates. BMC Biology 2014 12 13. (doi:10.1186/1741-7007-12-13)

17 Cobourne MT \& Green JB. Hedgehog signalling in development of the secondary palate. Frontiers of Oral Biology 201216 52-59. (doi:10.1159/000337543)
18 Davis LK, Meyer KJ, Rudd DS, Librant AL, Epping EA, Sheffield VC \& Wassink TH. Pax6 3' deletion results in aniridia, autism and mental retardation. Human Genetics 2008123 371-378. (doi:10.1007/ s00439-008-0484-x)

19 D'Elia AV, Pellizzari L, Fabbro D, Pianta A, Divizia MT, Rinaldi R, Grammatico B, Grammatico P, Arduino C \& Damante G. A deletion 3' to the PAX6 gene in familial aniridia cases. Molecular Vision $2007 \mathbf{1 3}$ $1245-1250$.

20 Lauderdale JD, Wilensky JS, Oliver ER, Walton DS \& Glaser T. $3^{\prime}$ deletions cause aniridia by preventing PAX6 gene expression. PNAS 200097 13755-13759. (doi:10.1073/pnas.240398797)

21 Wawrocka A, Budny B, Debicki S, Jamsheer A, Sowinska A \& Krawczynski MR. PAX6 3' deletion in a family with aniridia. Ophthalmic Genetics 201133 44-48. (doi:10.3109/13816810.2011. 615076)

22 Kleinjan DA, Seawright A, Schedl A, Quinlan RA, Danes S \& van Heyningen V. Aniridia-associated translocations, DNase hypersensitivity, sequence comparison and transgenic analysis redefine the functional domain of PAX6. Human Molecular Genetics 200110 2049-2059. (doi:10.1093/hmg/10.19.2049)

23 Kleinjan DA, Seawright A, Mella S, Carr CB, Tyas DA, Simpson TI, Mason JO, Price DJ \& van Heyningen V. Longrange downstream enhancers are essential for Pax6 expression. Developmental Biology 2006 299 563-581. (doi:10.1016/j.ydbio.2006.08.060)

24 Winkler GS, Petrakis TG, Ethelberg S, Tokunaga M, Erdjument-Bromage H, Tempst P \& Svejstrup JQ. RNA polymerase II elongator holoenzyme is composed of two discrete subcomplexes. Journal of Biological Chemistry 2001276 32743-32749. (doi:10.1074/jbc. M105303200)

25 Burri L, Strahm Y, Hawkins CJ, Gentle IE, Puryer MA, Verhagen A, Callus B, Vaux D \& Lithgow T. Mature DIABLO/Smac is produced by the IMP protease complex on the mitochondrial inner membrane. Molecular Biology of the Cell 200516 2926-2933. (doi:10.1091/mbc. E04-12-1086)

26 Nutt SL \& Busslinger M. Monoallelic expression of Pax5: a paradigm for the haploinsufficiency of mammalian Pax genes? Biological Chemistry 1999380 601-611. (doi:10.1515/BC.1999.077)

27 Rhoades KL, Singh N, Simon I, Glidden B, Cedar H \& Chess A. Allele-specific expression patterns of interleukin-2 and Pax-5 revealed by a sensitive single-cell RT-PCR analysis. Current Biology $2000 \mathbf{1 0}$ 789-792. (doi:10.1016/S0960-9822(00)00565-0)

28 van Raamsdonk CD \& Tilghman SM. Dosage requirement and allelic expression of PAX6 during lens placode formation. Development 2000 127 5439-5448.

Received 29 March 2014

Revised version received 15 July 2014

Accepted 22 October 2014 